\title{
Human SNM1A and XPF-ERCC1 collaborate to initiate DNA interstrand cross-link repair
}

\author{
Anderson T. Wang, ${ }^{1}$ Blanka Sengerová, ${ }^{1}$ Emma Cattell, ${ }^{1}$ Takabumi Inagawa, ${ }^{1,5}$ Janet M. Hartley, ${ }^{2}$ \\ Konstantinos Kiakos, ${ }^{2}$ Nicola A. Burgess-Brown, ${ }^{3}$ Lonnie P. Swift, ${ }^{1}$ Jacqueline H. Enzlin, ${ }^{1}$ \\ Christopher J. Schofield, ${ }^{4}$ Opher Gileadi, ${ }^{3}$ John A. Hartley, ${ }^{2}$ and Peter J. McHugh ${ }^{1,6}$ \\ ${ }^{1}$ Weatherall Institute of Molecular Medicine, University of Oxford, John Radcliffe Hospital, Oxford OX3 9DS, United Kingdom; \\ ${ }^{2}$ Cancer Research UK Drug-DNA Interactions Research Group, UCL Cancer Institute, University College London, London \\ WC1E 6BT, United Kingdom; ${ }^{3}$ Structural Genomics Consortium, University of Oxford, Oxford OX3 7DQ, United Kingdom; \\ ${ }^{4}$ Chemistry Research Laboratory, University of Oxford, Oxford, OX1 3TA, United Kingdom
}

\begin{abstract}
One of the major DNA interstrand cross-link (ICL) repair pathways in mammalian cells is coupled to replication, but the mechanistic roles of the critical factors involved remain largely elusive. Here, we show that purified human SNM1A (hSNM1A), which exhibits a 5'-3' exonuclease activity, can load from a single DNA nick and digest past an ICL on its substrate strand. hSNM1A-depleted cells are ICL-sensitive and accumulate replicationassociated DNA double-strand breaks (DSBs), akin to ERCC1-depleted cells. These DSBs are Mus81-induced, indicating that replication fork cleavage by Mus81 results from the failure of the hSNM1A- and XPF-ERCC1dependent ICL repair pathway. Our results reveal how collaboration between hSNM1A and XPF-ERCC1 is necessary to initiate ICL repair in replicating human cells.
\end{abstract}

[Keywords: DNA repair; interstrand cross-links; SNM1A exonuclease; XPF-ERCC1 endonuclease; metallo- $\beta$-lactamase family]

Supplemental material is available for this article.

Received June 6, 2011; revised version accepted July 20, 2011.

DNA interstrand cross-links (ICLs) present a serious threat to cellular survival and genomic integrity, because they inhibit fundamental processes such as DNA replication and transcription. For prokaryotes and lower eukaryotes (principally budding yeast), several major ICL repair pathways are partly characterized. Repair is initiated by incisions made by the nucleotide excision repair (NER) apparatus flanking the ICL (Cole and Sinden 1975; Jachymczyk et al. 1981; Miller et al. 1982; Van Houten et al. 1986; Sladek et al. 1989). The "unhooking" reaction produces a gapped intermediate covalently attached to the incised oligonucleotide. This intermediate is subject to further processing, which ultimately leads to gap filling by translesion synthesis (TLS), or homologous recombination $(\mathrm{HR})$ reactions where a sister chromatid is available (Sladek et al. 1989; Berardini et al. 1999; Sarkar et al. 2006). This gap-filled intermediate provides a substrate for removal of the cross-linked oligonucleotide,

${ }^{5}$ Present address: Department of Cell Biology and Genetics, Erasmus Medical Center, P.O. Box 2040, 3000 CA Rotterdam, The Netherlands. ${ }^{6}$ Corresponding author.

E-mail peter.mchugh@imm.ox.ac.uk.

Article is online at http://www.genesdev.org/cgi/doi/10.1101/gad.15699211. probably by a second round of NER excision (Sladek et al. 1989).

Data consistent with similar pathways operating in mammalian cells have been presented, particularly in nonreplicating cells (Smeaton et al. 2008; Muniandy et al. 2009). However, a critical difference between lower eukaryotes and mammalian cells is the increased ICL sensitivity of cells defective for the subunits of the XPF-ERCC1 heterodimeric nuclease complex in the latter (Hoy et al. 1985; Andersson et al. 1996; Damia et al. 1996; De Silva et al. 2000). It has been postulated that an XPF-ERCC1-dependent repair pathway is preferentially used during DNA replication. The principal evidence for this is that XPF- and ERCC1-defective cells accumulate replication-associated DNA double-strand breaks (DSBs) upon ICL induction (Niedernhofer et al. 2004). It has therefore been suggested that the encounter of a replication fork with an ICL triggers XPF-dependent repair events (Hanada et al. 2006). Consequently, it has been postulated that this DSB accumulation is due to either defective processing of the ICL at an early stage or a defect in unhooking during $S$ phase that prevents replication fork restoration, or that XPF-ERCC1 directly contributes to fork restart via a direct role in HR (Niedernhofer et al. 2004; Hanada et al. 2006; Bhagwat 
et al. 2009). It also remains possible that XPF-ERCC1 plays a dual role in both ICL unhooking and the downstream HR-mediated fork restart process. A number of cellular and biochemical studies indicate that XPF-ERCC1 can act to incise and process ICLs (Kuraoka et al. 2000; Mu et al. 2000; Fisher et al. 2008), although any role in ICLinduced recombination is not well characterized. Recently, several of these landmark steps during replication-coupled ICL repair have been directly examined using plasmids bearing a single, site-specific ICL in a Xenopus egg extract replication assay (Raschle et al. 2008). It was shown that ICLs efficiently stall the replication apparatus, and that unhooking incisions flanking the ICL occur following fork stalling, producing a DSB. Subsequent extension from the nascent leading strand coupled to ICL bypass by TLS then ensues, and finally, DSB repair by HR restores intact duplex plasmid DNA. The system employed involves forks converging from both directions, which is a plausible mechanism of ICL repair, although it is also likely that repair triggered by one fork meeting the ICL might induce repair effectively (Ben-Yehoyada et al. 2009; Shen et al. 2009; Nakanishi et al. 2011), but possibly involving different intermediates.

The yeast Pso2 repair factor plays a critical, specific, role in ICL repair (for review, see Cattell et al. 2010), but the mechanistic basis of its action remains unknown. In the absence of Pso2, yeast cells become highly ICL-sensitive and accumulate replication-associated DSBs (MaganaSchwencke et al. 1982; Li and Moses 2003; Barber et al. 2005). Moreover, studies from several groups have established that, unlike yeast NER mutants, pso2 mutants are competent for ICL unhooking (Magana-Schwencke et al. 1982; Wilborn and Brendel 1989; Meniel et al. 1995). Nonetheless, genetically, PSO2 is epistatic with NER factors, suggesting that Pso2 acts on a substrate generated following ICL incision by the NER complex (Henriques and Moustacchi 1981; Siede and Brendel 1982). The situation in mammalian cells is more complex, where three proteins with similarity to Pso2 have been identified: human SNM1A (hSNM1A), hSNM1B (Apollo), and hSNM1C (Artemis) (Aravind et al. 1999; Callebaut et al. 2002). In terms of domain organization, hSNM1A is most similar to Pso2, and, indeed, ectopic hSNM1A expression can partly rescue the ICL sensitivity of pso2 mutants (Hazrati et al. 2008). In addition, depletion of hSNM1A or disruption of mouse or chicken DT-40 SNM1A leads to mitomycin C (MMC) hypersensitivity, suggesting a role in ICL repair (Dronkert et al. 2000; Ishiai et al. 2004; Ahkter et al. 2005; Hemphill et al. 2008). While hSNM1C (Artemis)defective cells do not display hypersensitivity to ICLs, there are reports of hSNM1B-depleted cells displaying some sensitivity to ICLs and also to other genotoxins, including ionizing radiation (Demuth et al. 2004; Bae et al. 2008). Pso 2 and the hSNM1 family of proteins belong to the extended $\beta$-CASP metallo- $\beta$-lactamase (MBL) structural family of nucleases, recently reviewed in detail elsewhere (Cattell et al. 2010). All members of this family possess a catalytic domain that has structural similarity to the MBL family of prokaryotic antibiotic detoxifying enzymes, where the MBL structural domain has evolved to hydrolyze the phosphodiester backbone of nucleic acids (Callebaut et al. 2002). This has been confirmed for the hSNM1 family, where 5'-3' exonuclease activity has been demonstrated for hSNM1A and hSNM1B (Apollo), while hSNM1C (Artemis) is a structure-specific endonuclease (Ma et al. 2002; Li et al. 2005; Hazrati et al. 2008; Gu et al. 2010).

Here we show that cells depleted of hSNM1A are sensitive to ICLs, particularly those that are targeted to the minor groove of DNA. hSNM1A depletion leads to an accumulation of replication-associated DSBs, similar to ERCC1 depletion. Moreover, the DSBs formed upon depletion of hSNM1A and ERCC1 are Mus81-dependent. We found that the $5^{\prime}-3^{\prime}$ exonuclease activity of purified hSNM1A is not perturbed by the presence of an ICL on the substrate strand, and that hSNM1A is able to digest a DNA substrate containing a cross-linked strand starting from a single XPF-ERCC1-induced 5' nick. Together, our cellular and biochemical analysis is consistent with a simple, two-factor mechanism capable of initiating mammalian ICL repair.

\section{Results}

\section{Human cells depleted for hSNM1A are ICL-sensitive}

We initially sought to confirm the contribution of hSNM1A to ICL repair in human cells at the cellular level. We examined the ICL sensitivity profile of cells depleted of hSNM1A by siRNAs (Supplemental Fig. S1A,B). hSNM1Adepleted cells display differential sensitivity to clinically used ICL-inducing agents. Increased sensitivity was observed for cells depleted for hSNM1A with MMC (Fig. 1A), but only marginal sensitivity was observed with nitrogen mustard (HN2) (Supplemental Fig. S1D). MMC and HN2 produce structurally distinct ICLs: MMC reacts within the DNA minor groove to produce a minimally distorting cross-link that might only be recognized efficiently following replication fork collision, whereas $\mathrm{HN} 2$ reacts in the major groove to produce distorting ICLs (Norman et al. 1990; Noll et al. 2006). We also found that hSNM1Adepleted cells, like ERCC1-depleted cells, are sensitive to the rationally designed crosslinking drug SJG-136, which exclusively targets guanines in the minor groove, producing ICLs that confer low helical distortion (Fig. 1B, 3F [below]; Gregson et al. 2001). This confirms a role for hSNM1A in ICL repair, particularly in relation to minor groove ICLs; notably, the major endogenously generated interstrand cross-linking species, lipid peroxidation products, target the minor groove (Noll et al. 2006), indicating that minor groove ICLs might represent a major naturally occurring challenge to genome integrity.

\section{Digestion of ICL-containing DNA substrates by $h S N M 1 A$}

The molecular basis of hSNM1A/Pso2 action during ICL repair remains unknown, since their activity on DNA substrates containing ICLs has not been explored. To test this, we produced a high-quality recombinant truncated form of hSNM1A from Escherichia coli, and partially 
A

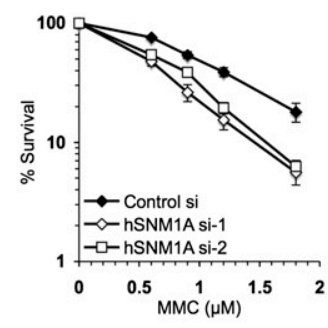

B

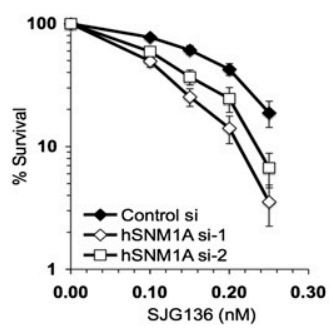

C

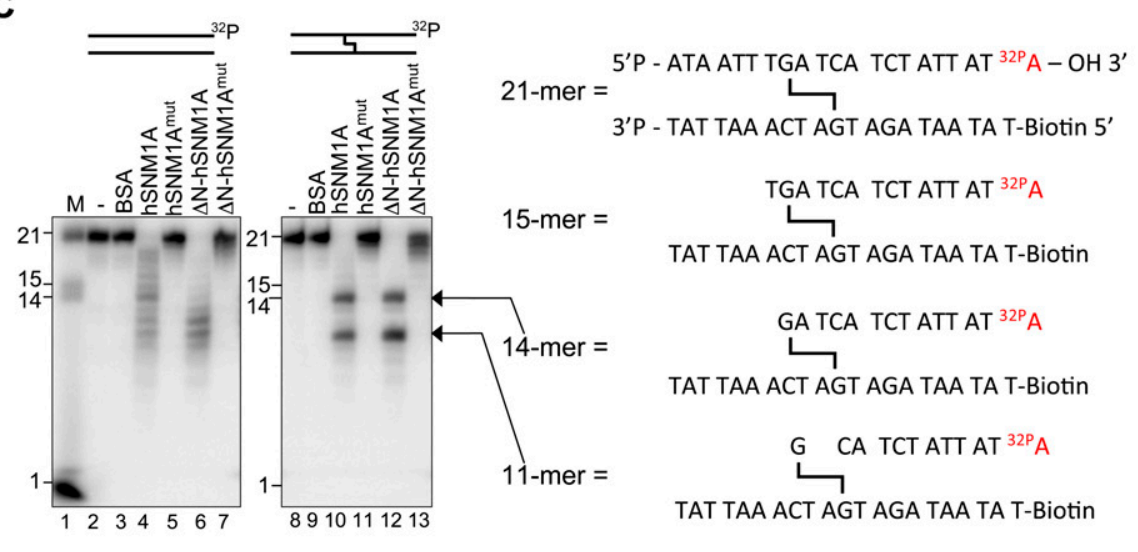

D

E

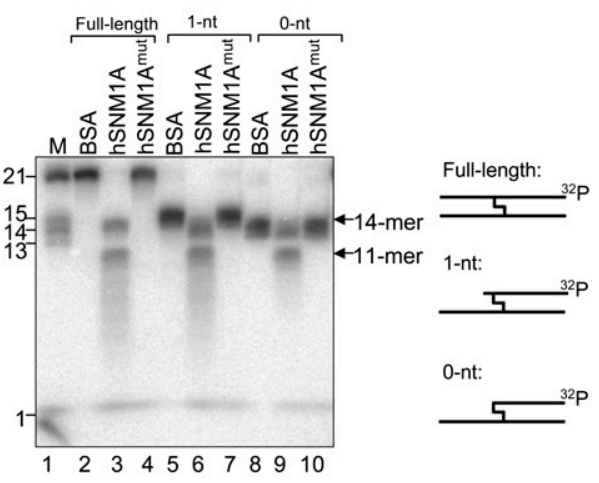

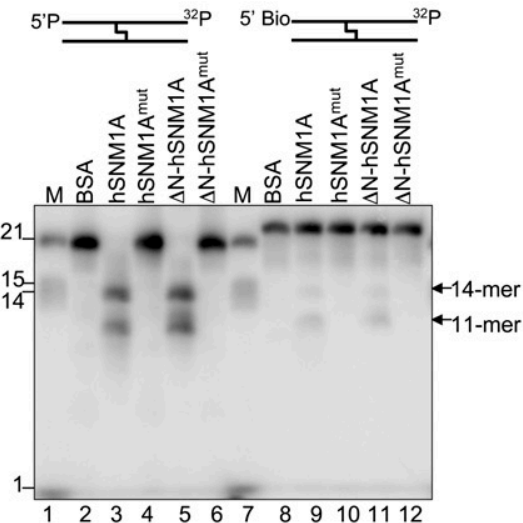

Figure 1. hSNM1A can degrade DNA containing an ICL. (A) A clonogenic survival assay was performed on HeLa cells transfected with two independent siRNAs targeting hSNM1A. Cells were treated with increasing doses of MMC for $1 \mathrm{~h}$. Error bars show standard error of the mean (SEM). (B) Clonogenic survival of siRNA transfected HeLa cells continuously incubated with increasing doses of SJG136. (C, left panel) Reaction products of hSNM1A on dsDNA (lanes 2-7) or SJG-136 cross-linked dsDNA (lanes 8-13). Hydrolysis was carried out in the absence of protein (lanes 2,8), or with BSA $(0.1 \mu \mathrm{g}$; lanes 3,9), full-length hSNM1A WT $(0.02 \mu \mathrm{g}$; lanes 4,10) or its cognate D736A mutant (0.02 $\mu \mathrm{g}$; lanes 5,11), or E. coli purified $\Delta$ N-hSNM1A (hSNM1A-[608-1040]) (0.0005 $\mu$ g; lanes 6,12) or its cognate D736A mutant (0.0005 $\mu \mathrm{g}$; lanes 7,13). (Lane 1) 3'-Labeled molecular weight marker oligonucleotides; sizes are indicated. (Right panel) Predicted identity of reaction products obtained based on molecular weight. $(D)$ Reaction $(30 \mathrm{~min})$ of hSNM1A with full-length ICL substrate (lanes 2-4), 1-nt "run-up" ICL substrate (lanes 5-7), or 0-nt "run-up" cross-linked dsDNA (lanes 8-10). Hydrolysis was carried out in the presence of BSA $(0.1 \mu \mathrm{g}$; lanes 2,5,8), full-length hSNM1A (lanes 3,6,9), or its D736A mutant form (lanes 4,7,10). (Lane 1) 3'Labeled marker oligonucleotides; sizes are indicated. (E) Reaction (30 min) of hSNM1A on cross-linked dsDNA, containing either 5' phosphate (lanes 2-6) or 5'-biotin (lanes 8-12). Hydrolysis was carried out with BSA $(0.1 \mu \mathrm{g}$; lanes 2,8), full-length hSNM1A (0.02 $\mu$; lanes 3,9) or its D736A mutant $(0.02 \mu \mathrm{g}$; lanes 4,10), or $\Delta \mathrm{N}$-hSNM1A $(0.0005 \mu \mathrm{g}$; lanes 5,11) or its D736A mutant $(0.0005 \mu \mathrm{g}$; lanes 6,12). (Lanes 1,6) 3'-Labeled molecular weight marker oligonucleotides; sizes are indicated.

purified full-length hSNM1A from yeast (Supplemental Fig. S2A; Hazrati et al. 2008). By truncating the first 607 amino acids of the $\mathrm{N}$ terminus of hSNM1A, we were able to produce a soluble 49-kDa protein in E. coli amenable to purification (Supplemental Fig. S2B). We found that the previously identified $5^{\prime}-3$ ' exonuclease activity of full-length hSNM1A is retained in recombinant hSNM1A(608-1040) ( $\triangle$ N-hSNM1A) (Supplemental Fig. S2C,D), and that both full-length hSNM1A and $\triangle$ N-hSNM1A exhibit a preference for ssDNA over dsDNA (Supplemental Fig. S2C,D; Hejna et al. 2007; Hazrati et al. 2008).

We then examined the activity of both full-length hSNM1A and $\triangle$ N-hSNM1A on substrates containing sitespecific SJG-136 ICLs (Supplemental Fig. S3). SJG-136 has major advantages for generating ICL substrates for biochemical analysis, including a high degree of sequence specificity, exceptionally high ICL yield, and also ICL heat reversibility that allows recovery of reaction products (Gregson et al. 2001; Rahman et al. 2009). The substrates we employed have a single centrally located ICL and are labeled with ${ }^{32} \mathrm{P}$ on their $3^{\prime}$ terminus on one strand only (Supplemental Fig. S3A,B). The complementary strand is blocked at the $5^{\prime}$ terminus to prevent competing exonuclease reactions that could complicate interpretation. Incubating this substrate with either full-length hSNM1A or $\Delta \mathrm{N}$-hSNM1A produces a characteristic reaction pattern, with major products corresponding to cleavage 1 nucleotide (nt) $5^{\prime}$ to the ICL on the strand under analysis and $2 \mathrm{nt}$ 
(third phosphodiester bond) $3^{\prime}$ to the ICL on this strand (Fig. 1C). There is also some further minor digestion past the second nucleotide $3^{\prime}$ to the ICL, suggesting that although digestion pauses three phosphodiester bonds $3^{\prime}$ to the ICL, it is not completely arrested at this point, at least in vitro. Importantly, both full-length hSNM1A and $\Delta$ N-hSNM1A proteins mutated at a critical active site aspartic acid (D736) in the putative MBL-type catalytic domain show greatly reduced nucleolytic activity (Fig. 1C). Because the exonuclease activity of hSNM1A is not highly processive (Supplemental Fig. S2C,D; data not shown), we then investigated whether hSNM1A has an increased capacity to digest past nucleotides involved in an ICL if they occur closer to the $5^{\prime}$ end of the substrate. We generated substrates where the ICL was preceded by a single nucleotide (" $\left.1 \mathrm{nt}^{\prime \prime}\right)$ or where the first nucleotide encountered at the $5^{\prime}$ terminus is the guanine involved in the cross-link ("0 nt") (Supplemental Fig. S3C,D,F). The activity of hSNM1A is not substantially affected by these configurations, yielding qualitatively and quantitatively similar products in each case (Fig. 1D).

The results described suggest that either (1) the exonuclease of hSNM1A can digest past, or over, the ICL (although pausing 5 ' to the ICL in some cases), or (2) the ICL is released by flanking incisions produced by a cryptic endonuclease activity. To differentiate between these possibilities, we blocked the 5' terminus of the strand under analysis with a biotin group. Blocking the $5^{\prime}$ terminus almost completely eliminates the hSNM1A-specific reaction (Fig. 1E) and, importantly, implies that hSNM1A possesses an exonucleolytic activity that can digest past the ICL. To further confirm this conclusion, we first performed $5^{\prime}$ postlabeling of the reaction products and analyzed the products using denaturing gels (Fig. 2A). We detected two products of $13 \mathrm{nt}$ and $10 \mathrm{nt}$, consistent with either termination of digestion immediately prior to the ICL, or step-wise exonucleolytic digestion proceeding to the third phosphodiester bond 3 ' to the ICL (Fig. 2B). If the two main cleavages we observed on the ICL-containing substrate (1 nt prior [5'] and $2 \mathrm{nt} 3^{\prime}$ to the ICL) were endonucleolytic, we would expect to release a 3-nt product: Such an intermediate was never observed in multiple analyses. In addition, the products of the hSNM1A reaction were confirmed in mass spectrometry analyses. Here, concentrated unlabeled "0-nt" substrate (molecular weight 11,497.18) (species 3 in Fig. 2D; also shown in Supplemental Fig. S3D) was hydrolyzed by hSNM1A, and the oligonucleotide components of the reaction mixture were analyzed by liquid chromatography and MALDI-TOF mass spectrometry (Fig. 2C). The results suggest that the cross-link is partially unstable under the conditions of the mass spectrometry analysis, as shown in Figure 2C ("substrate-only" column), and Figure 2D indicated the presence of partially broken down cross-linked substrates even in the absence of hSNM1A that could not be detected by extensive analysis of the same substrate by gel electrophoresis. More importantly, however, the presence of a 10-mer product (5'-pCATCTATTAT-OH-3'; calculated mass, 3057.01; experimentally determined mass, 3057.00) following hSNM1A treatment is likely to have resulted from translesion hydrolysis past the cross-link
A

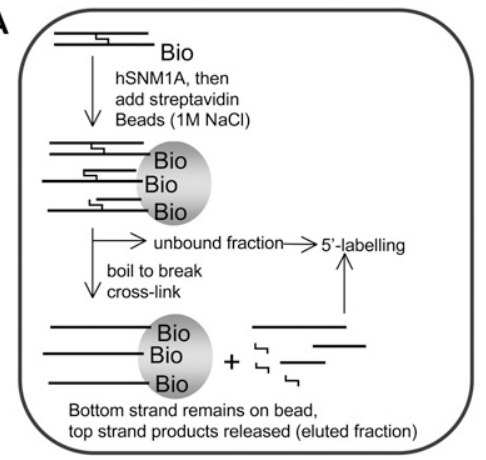

B

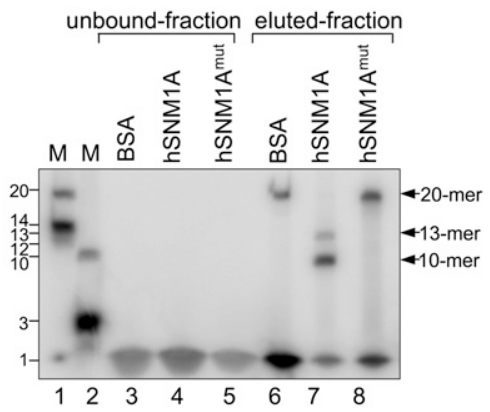

C

\begin{tabular}{|c|c|c|}
\hline Substrate & Species detected in 'substrate only' sample & $\begin{array}{l}\text { Unique species detected in 'substrate and } \\
\text { enzyme (reacted)' sample }\end{array}$ \\
\hline 0 -nt ICL & $\begin{array}{l}\text { 1) expected } 7493.61 \text {; observed } 7494 \text { - species } 1 \\
\text { 2) expected 6937; observed } 6937 \text { - species } 2 \\
\text { 3) expected } 11497.18 \text {; observed } 11498 \text { - species } 3 \\
\text { 4) expected } 4003.63 \text {; observed } 4004-\text { species } 4 \\
\text { 5) expected } 6146.03 \text {; observed } 6146 \text { - species } 8 \\
\text { 6) expected } 6050.95 \text {; observed } 6052 \text { - species } 9\end{array}$ & $\begin{array}{l}\text { 1) expected } 4598.00 \text {; observed } 4598 \text { - species } 5 \\
\text { 2) expected } 3057.01 \text {; observed } 3057 \text { - species } 6 \\
\text { 3) expected } 2767.83 \text {; observed } 2768 \text { - species } 7\end{array}$ \\
\hline
\end{tabular}

D Species: 1

3'P - TAT TAA ACT AGT AGA TAA TA T-Biotin 5'

2

3'P - TAT TAA ACT AGT AGA TAA TA T-Biotin 5'

3 5'P - GA TCA TCT ATT AT - OH $3^{\prime}$

3'P - TAT TAA ACT AGT AGA TAA TA T-Biotin 5'

4

5'P - GA TCA TCT ATT AT - OH 3'
5 5'P - T UGA TCA TCT ATT AT - OH 3'

6

5'P - A TCT ATT AT - $\mathrm{OH}^{\prime}$

8

5'P - ATA ATT UGA TCA TCT ATT AT - OH $3^{\prime}$

5'P - ATA ATT XGA TCA TCT ATT AT - OH 3'

$X=$ uracil post $U D G$ reaction
5'P - CA TCT ATT AT - OH 3'
Figure 2. Post-labeling of reaction products at the $5^{\prime}$ end with ${ }^{32} \mathrm{P}$ - $\gamma$-ATP suggests that hSNM1A hydrolysis past SJG-136 ICL is exonucleolytic. (A) Schematic diagram of experimental strategy. Substrate bearing a $5^{\prime}$ phosphate was reacted with full-length hSNM1A. The reaction products were immobilized on streptavidin-coated magnetic beads via the biotin moiety on the bottom strand. Boiling the beads releases the top strand product only, which was then post-labeled at the $5^{\prime}$ end with $\mathrm{T} 4$ polynucleotide kinase and $\left[{ }^{32} \mathrm{P}\right]-\gamma$-ATP. $(B$, lanes 1,2$) 5^{\prime}$-End-labeled marker oligonucleotides; sizes are as indicated. (Lanes 3-5) Unbound fraction following streptavidin immobilization of biotinylated hSnmlA reaction products labeled with T4PNK and ${ }^{32} \mathrm{P}-\gamma$-ATP. (Lanes 6-8) Streptavidinbound fraction labeled with T4PNK and $\gamma-{ }^{32} \mathrm{P}$-ATP after boiling to break the crosslink and removal of magnetic beads. The reactions contained either BSA (lanes 3,6) or full-length hSNM1A (lanes 4,7 ) or its cognate D736A mutant (lanes 5,8). LC-MS confirmed the identity of the hSNM1A reaction products. $(C)$ Experimental and expected masses of the species observed in the experimental mixtures analyzed by mass spectrometry. $(D)$ Structures of the species referred to in $C$. 
\{Fig. 2C ["substrate and enzyme (reacted)" column], D\}. In addition, a shorter product was also detected, a 9-mer (5'-pATCTATTAT-OH-3'; expected mass, 2767.83; experimentally determined mass, 2768.00), confirming that although pausing will occur opposite the cross-linked base of the bottom strand, the 10-mer product can be hydrolyzed further (see also Fig. 1C,D). As before, no 3-mer was detected.

\section{hSNM1A-depleted cells accumulate replication-associated DSBs following ICL induction}

We next examined the consequence of hSNM1A depletion during ICL processing to gain insights into its cellular role. Previous work indicates that minimally distorting ICLs persist into $S$ phase, escaping detection by global NER, and are instead detected as a result of replication fork collision (Akkari et al. 2000; Raschle et al. 2008; Smeaton et al.
2008), associated with fork cleavage and DSB induction (De Silva et al. 2000; Niedernhofer et al. 2004; Hanada et al. 2006). We found that following hSNM1A depletion, MMC treatment produced a marked increase in MMCinduced $\gamma \mathrm{H} 2 \mathrm{AX}$ foci in both HeLa and U2OS cells (Fig. 3A,B,C; data not shown), similar to ERCC1-depleted cells (Fig. 3G; Niedernhofer et al. 2004). Pulsed-field gel electrophoresis (PFGE) confirmed that the $\gamma \mathrm{H} 2 \mathrm{AX}$ foci observed in hSNM1A- and ERCC1-depleted cells indicate induction of DSBs (Fig. 3D). These data imply that hSNM1A participates in the same pathway as XPF-ERCC1 during ICL processing. Consistent with this, codepletion of hSNM1A and ERCC1 produced no further increase in MMC or SJG136 sensitivity (Fig. 3E,F) or induction of $\gamma \mathrm{H} 2 \mathrm{AX}$ (Fig. 3G). hSNM1A- and ERCC1-depleted cells pass through S phase with normal kinetics following MMC treatment, excluding the possibility that the increase in DSBs is due to cell cycle perturbation (Fig. 3H; Supplemental Fig. S4).
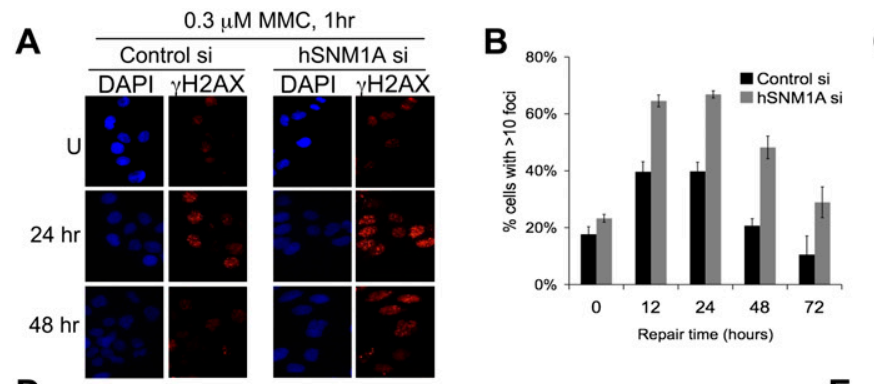

D

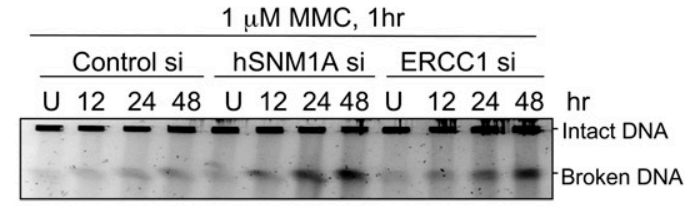

C

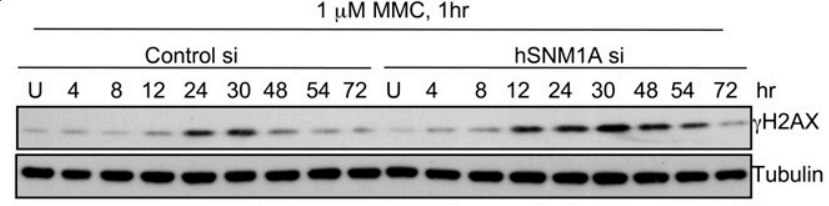

$\mathbf{G}$

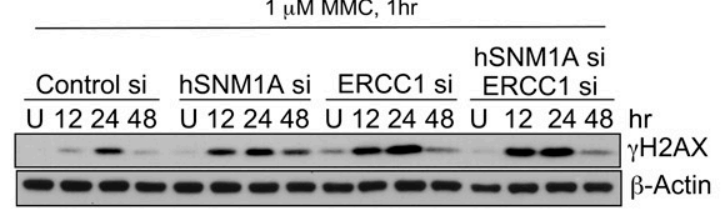

H
$\mathbf{E}$

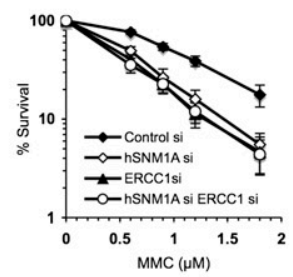

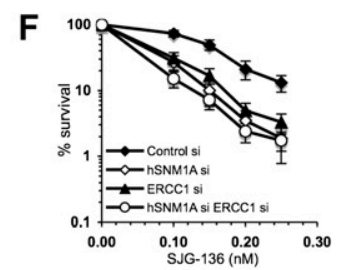

$1 \mu \mathrm{M} M M C, 1$ hour

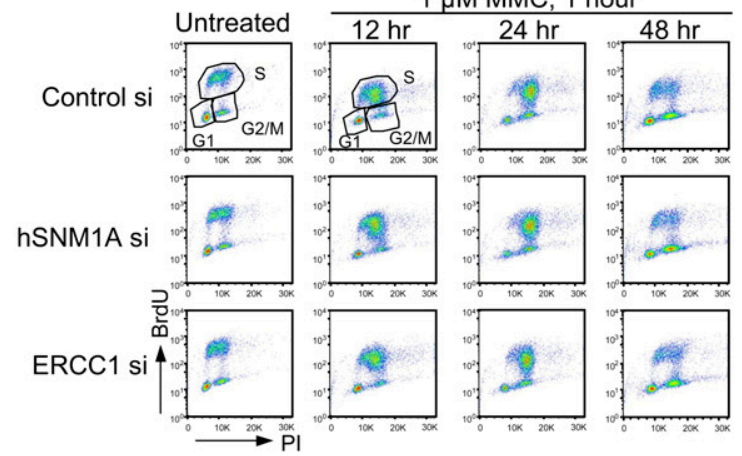

Figure 3. Depletion of hSNM1A leads to the accumulation of ICL-associated DSBs. (A) HeLa cells transfected with indicated siRNAs were seeded on glass coverslips before treatment with $0.3 \mu \mathrm{MMMC}$ for $1 \mathrm{~h}$. Cells were fixed at the indicated time points before staining with $\gamma \mathrm{H} 2 \mathrm{AX}$ antibodies and DAPI. (B) Quantification of slides from $A$ for percentage of cells with $>10 \gamma \mathrm{H} 2 \mathrm{AX}$ foci. Values represent the averages \pm SEM of blind scoring from three independent experiments. $(C)$ HeLa cells transfected with indicated siRNAs were treated with $1 \mu \mathrm{M} M M C$ for $1 \mathrm{~h}$, then incubated in drug-free medium for the indicated time. The levels of $\gamma \mathrm{H} 2 \mathrm{AX}$ were determined by immunoblotting. (D) DSB formation was directly detected by PFGE. $(E, F)$ HeLa cells were transfected with control siRNA, siRNAs against hSNM1A, or ERCC1 or in combination. Clonogenic survival assays were carried out as described in Figure 1. $(G) \gamma \mathrm{H} 2 \mathrm{AX}$ activation kinetics in cells depleted for hSNM1A, ERCC1, or both factors following MMC treatment. $(H)$ Cell cycle profile after treatment with 1 $\mu \mathrm{M} M M C$ for $1 \mathrm{~h}$. HeLa cells were incubated in drug-free medium after drug treatment and were harvested at the indicated time. Samples were analyzed by FACS, and the cell cycle profiles were presented as BrdU incorporation versus PI staining. 
The ICL-associated DSBs that accumulate in hSNM1A- or ERCC1-depleted cells are induced by Mus81

Mus81 has been implicated in the formation of DSBs at ICL-stalled replication forks (Hanada et al. 2006). Strikingly, the accumulation of $\gamma \mathrm{H} 2 \mathrm{AX}$ in asynchronous hSNM1A- or ERCC1-depleted cells is strongly suppressed by Mus81 depletion (Fig. 4A), as is the broken DNA detected by PFGE (Fig. 4B). In cells treated with MMC while held at the G1/S boundary and then allowed to pass synchronously passing though $\mathrm{S}$ phase, $\gamma \mathrm{H} 2 \mathrm{AX}$ is also suppressed by Mus 81 depletion (Supplemental Fig. S5A,B). Therefore, the ablation of $\gamma \mathrm{H} 2 \mathrm{AX}$ is not due to impaired progression through $\mathrm{S}$ phase (Supplemental Fig. S5A). Mus81-depleted cells are sensitive to MMC but to a lesser extent than hSNM1Adepleted cells (Fig. 4D). hSNM1A and Mus81 doubledepleted cells phenocopied Mus81-depleted cells modestly but highly reproducibly, suppressing sensitivity compared with cells depleted of hSNM1A alone (Fig. 4D). The latter observation suggests that there are deleterious consequences arising when Mus81 cleaves forks stalled at ICLs and hSNM1A is not available to process the intermediate generated, preventing the downstream re-establishment of replication forks.

The recently described Slx 4 factor has been proposed to act as a "docking" platform to coordinate some of the activities of the XPF/Mus81/Slx1 nuclease family (Fekairi et al. 2009; Svendsen et al. 2009). Moreover, it has recently been demonstrated that Slx 4 is mutated in a form of Fanconi anemia (complementation group P) (Crossan et al. 2011; Kim et al. 2011; Stoepker et al. 2011). Depletion of Slx4 produces an increase in MMC-induced DSBs (Fig. 4C). Cells depleted of both Slx4 and hSNM1A show activation of $\gamma \mathrm{H} 2 \mathrm{AX}$ similar to single knockdown cells (Fig. $4 \mathrm{C})$, and the $\gamma \mathrm{H} 2 \mathrm{AX}$ that accumulates in Slx4-depleted cells is Mus81-dependent (Fig. 4C). Finally, double depletion of Slx4 and hSNM1A resulted in a very similar level of sensitivity to MMC (Fig. 4E), confirming that Slx4/ FANCP also participates in the XPF-ERCC1/hSNM1A branch of ICL repair.

Collectively, our cellular studies demonstrate that hSNM1A plays a key role in the processing of ICLs within the same pathway as XPF-ERCC1, and failure of this pathway leads to the accumulation of Mus81-induced DSBs during $S$ phase. Interestingly, ICL detection and checkpoint activation, as determined by FANCD2 monoubiquitination and Chk1 Ser 317 phosphorylation, precede $\gamma \mathrm{H} 2 \mathrm{AX}$ induction by several hours (Fig. $4 \mathrm{~F}$ ), indicating that DSB formation is a relatively late response to ICLs, becoming a major response only if the pathway controlled by XPF-ERCC1 and hSNM1A fails.

\section{hSNM1A can digest ICL-containing DNA from a single 5' nick}

We aimed to test directly whether hSNM1A and XPFERCC1 are able to collaborate to initiate ICL repair, asking

\section{A}

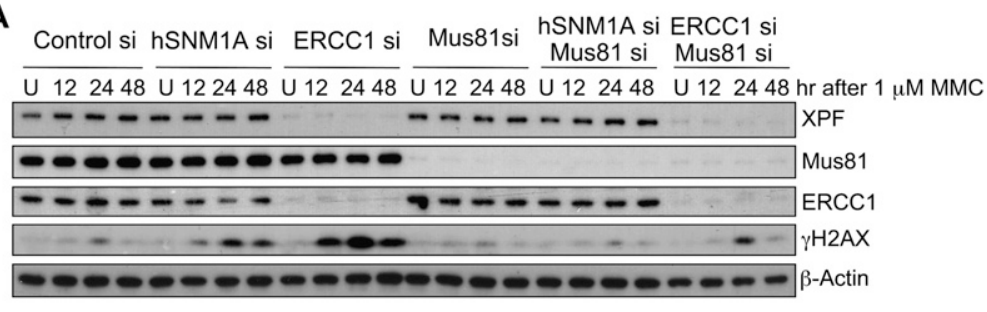

B
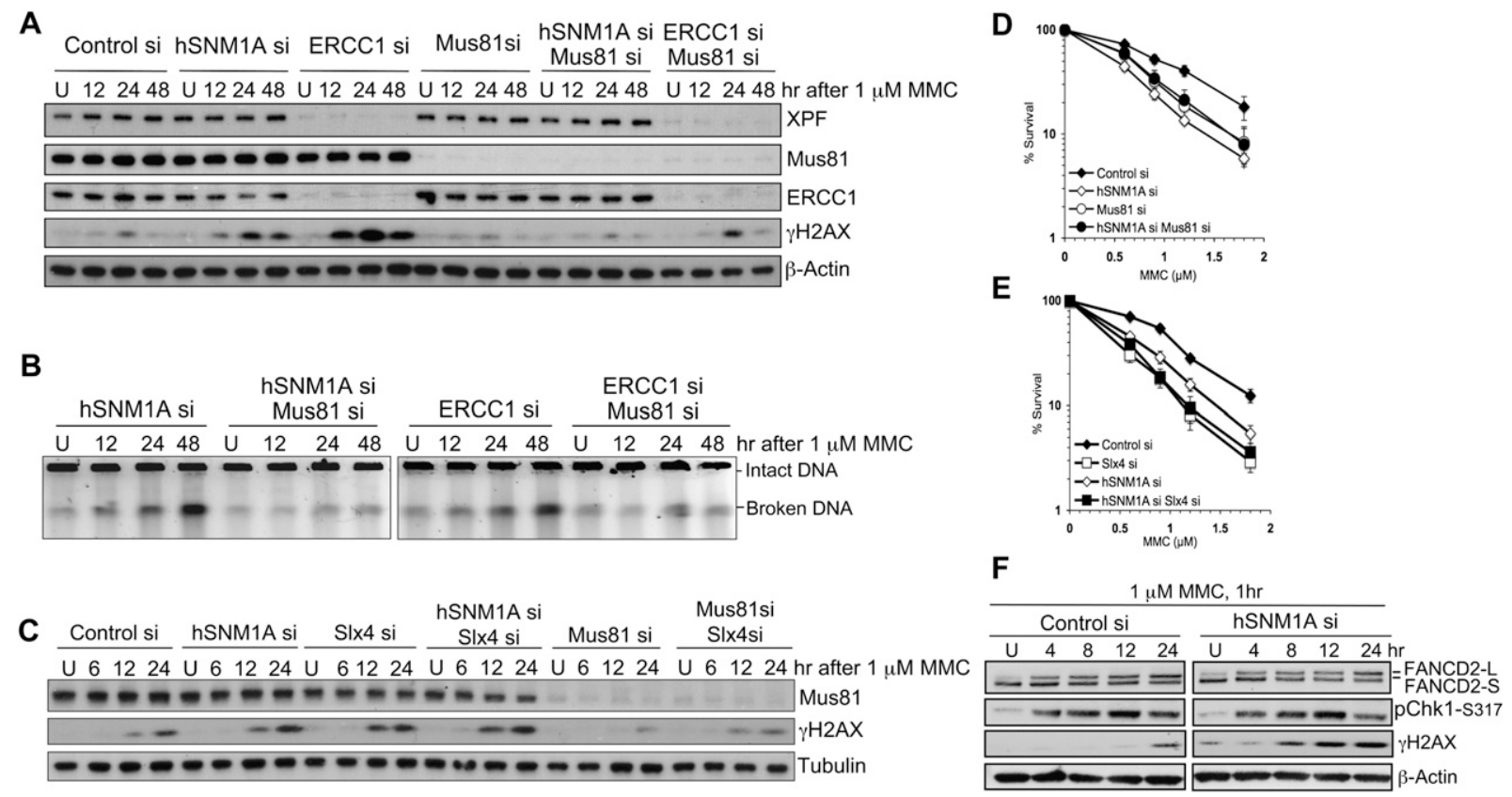

Figure 4. Mus81 depletion suppresses $\gamma \mathrm{H} 2 \mathrm{AX}$ activation in response to ICLs in HeLa cells. $(A)$ Cells transfected with the indicated siRNAs were treated with $1 \mu \mathrm{M} M M C$ for $1 \mathrm{~h}$ and then incubated in drug-free medium after drug treatment and harvested at the indicated time. Expression levels of proteins were detected by immunoblotting. $(B)$ Amount of broken DNA from cells described in $A$ was analyzed by PFGE. (C) Immunoblotting showing $\gamma \mathrm{H} 2 \mathrm{AX}$ levels in cells transfected with the indicated siRNAs and treated with MMC. $(D, E)$ Clonogenic survival of cells transfected with indicated siRNAs following $1 \mathrm{~h}$ of MMC treatment. $(F) \gamma \mathrm{H} 2 \mathrm{AX}$, Chk1-ser317 phosphorylation, and FANCD2 monoubiquitination (which produces FANCD2-L) were monitored in control and hSNM1A-depleted cells after MMC. 
whether hSNM1A can process ICLs from a single nick 5' to the ICL. An initial incision-for example, by XPFERCC1-could be sufficient to provide a substrate for hSNM1A. We generated a 61-mer substrate where the 5' end of both DNA strands was blocked with biotin (Supplemental Fig. S3E), and a single nick was then introduced $20 \mathrm{nt}$ upstream of the ICL by the action of the Nt.CviPII nuclease. This is a good substrate for hSNM1A (Fig. 5A), generating a pattern of digestion both quantitatively and qualitatively similar to that previously seen with the 5' phosphate provided at a blunt double-stranded end.

Finally, therefore, we tested whether purified XPFERCC1 and hSNM1A can initiate repair of a site-specific ICL in vitro. Following incubation of the 61-mer substrate containing a site-specific SJG-136 ICL, XPF-ERCC1 induces incisions 2 or $3 \mathrm{nt} 5^{\prime}$ to the ICL in a time-dependent fashion (Fig. 5B). When XPF-ERCC1 treatment is followed by the addition of hSNM1A, we observe a typical exonucleolytic hSNM1A ICL digestion pattern, terminating $2 \mathrm{nt}$ past ( $3^{\prime}$ to) the ICL (Fig. 5B). A second product of $\sim 50 \mathrm{nt}$, representing cleavage $17 \mathrm{nt} 5^{\prime}$ to the ICL (Fig. 5B), is also observed. We suggest that some alteration to the secondary structure of the substrate due to the presence of the ICL must account for this. Indeed, both the XPF-ERCC1induced incision and hSNM1A exonucleolytic processing of these substrates are completely ICL-specific, since a control duplex lacking the SJG-136 lesion was not subject to digestion by either nuclease (Supplemental Fig. S6). Therefore, the SJG-136 ICL is a substrate for XPFERCC1, and XPF-ERCC1-induced incisions provide access for hSNM1A to digest past the ICL. Our combined biochemical data imply that hSNM1A is capable of digesting through ICLs from a DSB end or a nick 5' to the cross-link, producing a gapped substrate suitable for further processing in TLS and/or HR reactions.

\section{Discussion}

Here we identified a role for the hSNM1A protein in ICL repair through cellular and biochemical approaches. Our studies also demonstrate that hSNM1A works in a common pathway with XPF-ERCC1 during replication-associated ICL repair. The repair of ICLs requires the concerted action of multiple repair pathways (Dronkert and Kanaar 2001). Incision around the lesion to allow the unhooking of the ICL from one of the two strands represents a pivotal step in initiation of the repair process. A number of nucleases have been suggested to play such a role in this step, including XPF, Mus81, and FAN-1. Based on the observation that mus81-/mouse embryonic fibroblasts (MEFs) showed suppression of DSBs (Hanada et al. 2006), whereas ercc1 ${ }^{-/-}$MEFs accumulate DSBs (Niedernhofer et al. 2004), several investigators, including ourselves, have previously proposed a model of ICL repair in which initiation of incision by Mus81, possibly on the leading strand template of the replication fork, is followed by a second XPF-ERCC1-dependent incision $5^{\prime}$ to the ICL, where the net result is unhooking. This step is accepted to be a prerequisite for downstream repair processes such as TLS and HR (Niedernhofer et al. 2004; Hanada et al. 2006; Bhagwat et al. 2009). However, evidence for the order of events in which Mus81 and XPF/ERCC1 participate has remained inconclusive.

In this study, we found that depleting hSNM1A produced an increase in DSBs reminiscent of ERCC1 and Slx4/FANCP depletion (Fig. 3). We also found that the formation of excess DSBs observed in ERCC1-, Slx4/
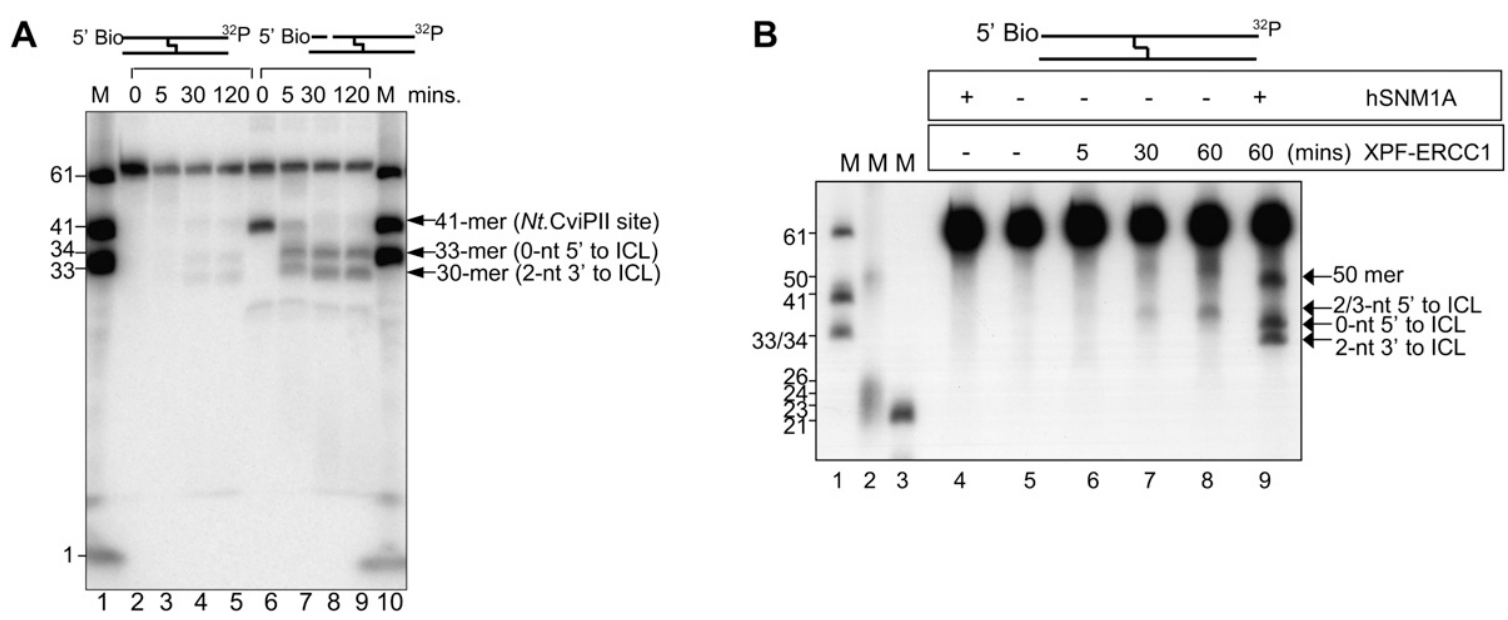

Figure 5. hSNM1A can digest ICL-containing duplex DNA starting from XPF-induced incision. $(A)$ Time course of hSNM1A hydrolysis of blocked (5'-biotinylated) and singly nicked cross-linked substrates by full-length hSNM1A. (Lane 1) 3'-End-labeled marker oligonucleotides; lengths are as indicated. (Lanes 2-5) Hydrolysis of blocked dsDNA 61-mer after 0 min (lane 2), 5 min (lane 3), 30 min (lane 4), or 120 min (lane 5). (Lanes 6-9) Hydrolysis of blocked dsDNA 61-mer treated with Nt.CviPII to introduce a site-specific nick $20 \mathrm{nt}$ from the 5' end (at nucleotide 41) after $0 \mathrm{~min}$ (lane 6), $5 \mathrm{~min}$ (lane 7), $30 \mathrm{~min}$ (lane 8), or $120 \mathrm{~min}$ (lane 9). The guanine that is involved on the ICL on the labeled strand is at position 33 from the $5^{\prime}$-end. (B) Reaction of XPF-ERCC1 and $\triangle$ N-hSNM1A on blocked (5'-biotinylated) cross-linked substrate. (Lanes 1-3) 3'-Labeled (lanes 1,3) or 5'-labeled (lane 2) marker oligonucleotides; sizes are indicated. (Lane 5) Unreacted substrate. (Lane 4) Reaction containing $\Delta$ N-hSNM1A only. (Lanes 6-8) Reaction containing XPF-ERCC1, stopped after 5 min (lane 6), 30 min (lane 7), or $60 \mathrm{~min}$ (lane 8). (Lane 9) Reaction with XPF-ERCC1 for $60 \mathrm{~min}$, followed by reaction with $\Delta$ N-hSNM1A for $30 \mathrm{~min}$. 
FANCP-, or hSNM1A-depleted cells was suppressed by Mus81 depletion (Fig. 4A,B; Supplemental Fig. S5), implying that Mus 81 acts on repair intermediates that persist in the absence of the XPF-ERCC1/Slx4/hSNM1A-controlled repair pathway. Given that the cells were treated with the same dose of MMC, which did not significantly alter the cell cycle progression profiles of these cells, if the cleavage of a stalled fork structure by Mus81 was to be the initiating event of the repair during S phase, the peak level of DSBs would not be expected to be increased by loss of ERCC1 or hSNM1A. This argues against Mus81 producing the initiating incisions during ICL repair. In addition, for both control and hSNM1A- and ERCC1-depleted cells, the $\gamma \mathrm{H} 2 \mathrm{AX} / \mathrm{DSB}$ levels peaked when cells were in late S/G2 phase, many hours after the activation of ATR signaling by the stalled replication fork, as evidenced by the peak level of Chk1 phosphorylation (Fig. 4F) and FANCD2 ubiquitination (Fig. 4F; Supplemental Fig. S5B), both of which substantially precede DSB accumulation. Together, these indicate that Mus81-dependent cleavage of the replication fork is a relatively late event that is triggered when the XPF-ERCC1/hSNM1A pathway fails.

Our biochemical analysis identified a novel activity for hSNM1A that is consistent with a role in processing incised ICL repair intermediates. When incubated with substrates containing site-specific ICLs, hSNM1A was able to digest the substrate exonucleolytically, progressing past the point of the ICL. Where translesion digestion occurs, the product is most likely to be a single nucleotide covalently crosslinked to the opposing strand. All current models of replication-associated ICL repair posit that the gapped intermediate remaining following ICL incision is then a substrate for TLS. However, biochemical studies have revealed that TLS does not occur efficiently when an oligonucleotide remains tethered to the template DNA strand (Minko et al. 2008). However, if a single or few nucleotides remain covalently linked, then such an intermediate becomes a good substrate for TLS (Minko et al. 2008), and such an intermediate is produced following the action of hSNM1A. Importantly, hSNM1A can achieve this digestion when its entry point is a single nick $5^{\prime}$ to the ICL, as produced by XPF-ERCC1, which should be considered the minimal initiating step for ICL repair by such a pathway.

Taken together, therefore, our experiments indicate that XPF-ERCC1 collaborates with hSNM1A to initiate ICL repair. Following replication stalling at some distance from the ICL (Raschle et al. 2008), XPF-ERCC1 plays a critical role in incising the ICL, as supported by numerous other biochemical and cellular studies (De Silva et al. 2000; Kuraoka et al. 2000; Niedernhofer et al. 2004), although it is also possible that the newly identified FAN-1 nuclease contributes to this step. This provides an access point for hSNM1A to digest the residual cross-linked oligonucleotide, producing a gapped intermediate tethering a covalently linked mononucleotide. Such structures are good substrates for gap filling by TLS that restores an intact template strand, which ultimately permits the completion of DNA replication (Minko et al. 2008). Based on this, we propose three context-dependent ICL repair models (Fig. 6) in which the targeting of the initial XPF-ERCC1/hSNM1A reactions influences subsequent steps; specifically, whether the incisions are directed to the leading or lagging strand templates (pathways A and B, respectively), or where incision occurs in the context of converging forks (pathway C) (Raschle et al. 2008). Importantly, in each case it is clear that initial processing by XPF-ERCC1 and hSNM1A would be sufficient for the efficient lesion bypass pivotal to replication fork restoration. Indeed, our results show that processing by hSNM1A and XPF-ERCC1 is the primary ICL repair-initiating event, avoiding Mus81-induced fork cleavage, which evidently represents a backup strategy for repairing ICLs. However, under circumstances where ICLs persist-for example, if the XPF-ERCCl/hSNM1A pathway fails or is overwhelmed-forks may converge more frequently on ICLs, and in this scenario, Mus81-dependent fork cleavage could provide an alternative means to allow repair and the completion of replication (Fig. 6). Our data and the recent work of others suggest that there is more than one system for the repair of ICLs (Raschle et al. 2008; Ben-Yehoyada et al. 2009; Shen et al. 2009). Depending on the temporal and spatial context in which ICLs are detected-by either a single replication fork, converging forks, or other mechanisms-different nucleases are recruited to the sites of ICLs. In all models, generation of a $5^{\prime}$ nick would provide an entry point for hSNM1A to produce translesion digestion past the ICL. The replicative and translesion polymerases involved in the subsequent leading strand synthesis (Raschle et al. 2008) or gap repair can then efficiently extend past the tethered ICL. Therefore, regardless of the order of initiating ICL incision events under different conditions, it seems that the activity of hSNM1A would aid ICL resolution in the context of all current models.

Clearly, the regulation of the choice of repair mechanism represents the next major challenge in the field. Our data indicate that Slx4/FANCP acts in the same pathway as XPF-ERCC1 and hSNM1A. Given that chromatin recruitment of XPF-ERCC1 is dependent on Slx4/FANCP (Crossan et al. 2011; Kim et al. 2011; Stoepker et al. 2011), it is plausible that Slx4/FANCP acts to switch on the XPFERCC1- and hSNM1A-dependent pathway. Moreover, it has recently been suggested that Rad18 and ubiquitinated PCNA might be involved in the targeting of hSNM1A to damaged replication forks (Yang et al. 2010). Further understanding of the mechanisms and structural requirements for activation and recruitment of FANCD2-FANCI, Slx4/FANCP, and repair nucleases to sites of ICL-induced stalled replication forks will help cement the details of this critical human DNA repair pathway.

\section{Materials and methods}

\section{Cell culture, RNAi, and plasmid transfection}

HeLa cells and U2OS cells were obtained from Cancer Research UK Clare Hall Cell Services and maintained in RPMI 1640 supplemented with $10 \%$ fetal calf serum and glutamine without antibiotics. For performing RNAi, cells were transfected with the indicated siRNA duplexes ( $5 \mathrm{nM}$ or $20 \mathrm{nM}$ ) using Hiperfect transfection reagent (Qiagen) according to manufacturer's recommendation. siRNA transfected cells were harvested for subsequent drug treat- 


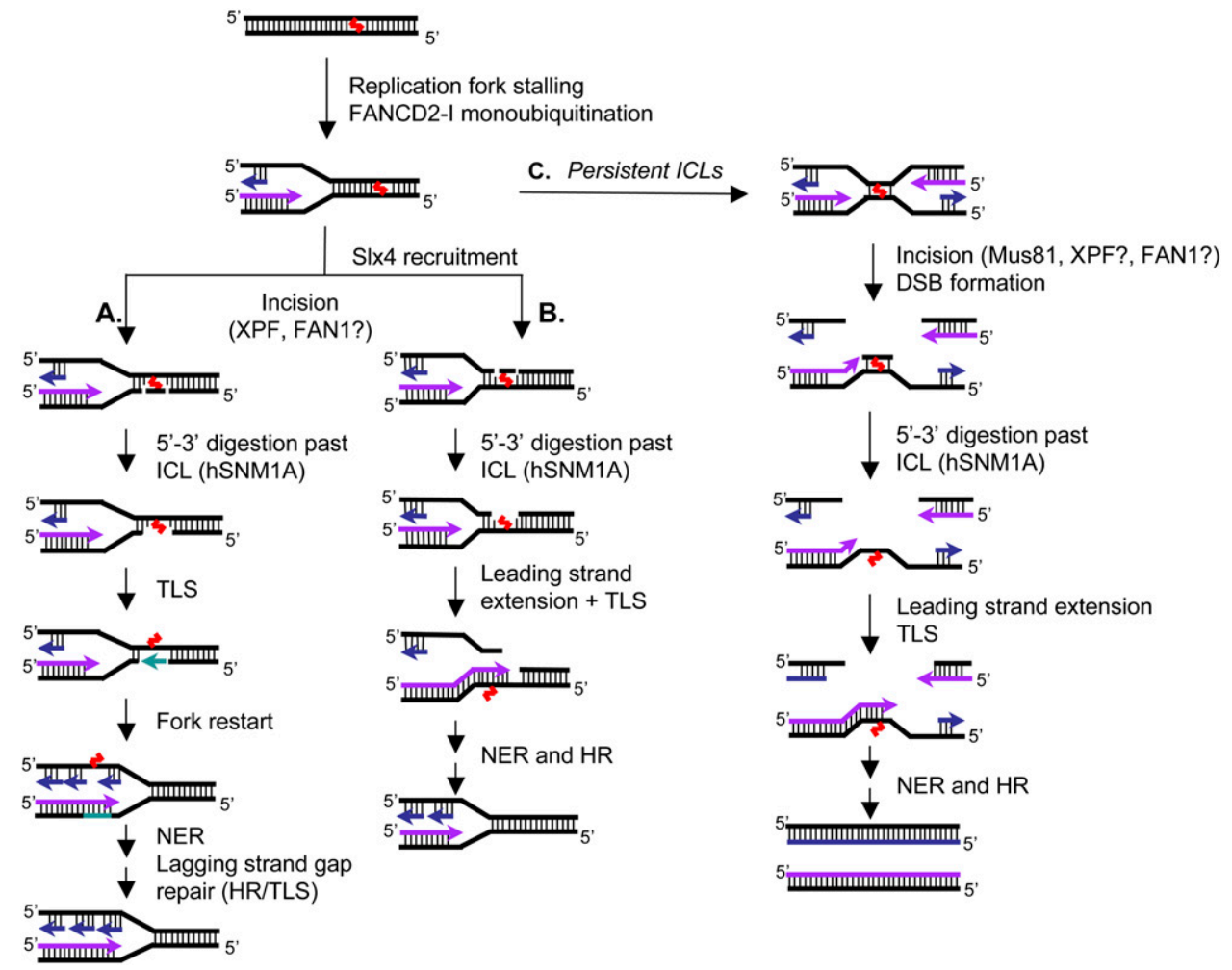

Figure 6. Models for context-dependent ICL repair during replication. Following replication fork stalling in the vicinity of the ICL, FANCD2-FANCI becomes activated and in turn orchestrates the repair of ICLs. The repair is initiated by XPF-ERCC1-dependent incisions, either $5^{\prime}$ to the lesion alone or by flanking incisions. Slx4 may help to target XPF-ERCC1 to the site of the ICLs at such structures. Following ICL incision, hSNM1A is able to digest the cross-linked oligonucleotide, leaving a single nucleotide tethered to the complementary strand. The initial incisions could be on either the leading or lagging strand. (A) Should the incision and processing reaction be targeted to the leading strand template, TLS gap filling would produce an intact template for the progression of the nascent leading strand, with a gap remaining in the nascent lagging strand that can be repaired/filled post-replicatively by TLS or HR. $(B)$ Conversely, incision on the lagging strand would allow the leading strand to directly extend past the ICL lesion. Break-induced repair by HR can then take place to re-establish the replication fork. $(C)$ In the situation when two replication forks converge on an ICL, most likely during late $S$ phase, initial incisions could still be produced by XPF-ERCC1, with post-incision processing by hSNM1A. Where XPF-ERCC1 is impaired, the converging fork pathway might predominate due to the failure to initiate repair following the arrival of the first fork, but under such circumstances, we suggest that here Mus 81 could be recruited as an alternative means of incising the ICL, generating a two-ended DSB. Following extension of leading strand synthesis past the remaining ICL adduct, HR can restore the replication fork through DSB repair, allowing completion of DNA synthesis.

ment $72 \mathrm{~h}$ after transfection. The siRNA duplexes used in this study are listed in Supplemental Table S1. As negative controls, cells were transfected with AllStars RNAi negative control duplex from Qiagen. The pEGFP-C1 plasmid encoding full-length hSNM1A cDNA was a kind donation from M. Takata (Ishiai et al. 2004). Plasmid transfection was performed using Lipofectamine 2000 (Invitrogen) according to the manufacturer's recommendation.

\section{Clonogenic survival assay}

Following transfection with relevant siRNAs, cells were seeded in 10-cm dishes at a density of 1000 cells per dish and allowed to adhere overnight before the appropriate drug treatment. Cells were then incubated for $12 \mathrm{~d}$ to allow colony formation. The plates were stained with Coomassie Brilliant Blue solution and rinsed under water. Colonies with $>50$ cells were counted.

Immunoblotting, indirect immunofluorescence, and antibodies

Whole-cell extracts for immunoblotting were prepared by lysing cells in Laemmli sample buffer (2\% SDS, 10\% glycerol, $62.5 \mathrm{mM}$
Tris-HCl at $\mathrm{pH}$ 6.8). Indirect immunofluorescence was performed as described previously (Chan et al. 2009). Cells positive for $\gamma \mathrm{H} 2 \mathrm{AX}$ foci were defined as having $>10$ foci. At least 250 cells were counted blind. The antibodies and dilutions used are listed in Supplemental Table S2.

\section{PFGE}

Cells treated with MMC for $1 \mathrm{~h}$ were harvested by trypsinization. The preparation and processing of agarose plugs containing $1 \times 10^{6}$ cells and the separation of broken DNA from intact genomic DNA by agarose gel eletrophoresis were carried out as previously described (Hanada et al. 2006). SYBR gold nucleic acid gel stain solution (Invitrogen) or ethidium bromide was used for staining DNA. Images of the gel were captured using AlphaImager HP transilluminator (Alpha Innotech).

\section{5-Bromo-2-deoxyuridine (BrdU) incorporation and flow cytometry analysis}

Cells were incubated with $10 \mu \mathrm{M}$ BrdU for $30 \mathrm{~min}$ before harvesting. Cells pelleted for flow cytometry analysis were first 
fixed in $70 \%$ ethanol, followed by acid denaturation. After neutralizing in $\mathrm{Na}_{2} \mathrm{~B}_{4} \mathrm{O}_{7}$, cells were incubated with rat anti-BrdU antibody (Abcam). An FITC-conjugated secondary antibody was added after the primary antibody was removed by centrifugation. Cells were then resuspended in propidium iodide solution $(25 \mu \mathrm{g} /$ $\mathrm{mL}$ ) to stain nucleic acids. A Cyan flow cytometer with Summit software (Dako) was employed to analyze samples. The FL2-H channel was used to detect the PI signal, whereas the presence of BrdU was detected as the FITC signal. The distribution of cells in G1, early and late S, and G2 phases were determined when log FITC was plotted against linear FL2-H (PI) by FlowJo software.

\section{Purification of hSNM1A}

Full-length hSNM1A was purified from yeast, as described (Hazrati et al. 2008), with an additional Heparin column step using a gradient of $100-1000 \mathrm{mM} \mathrm{NaCl}$ in buffer $(50 \mathrm{mM}$ Tris- $\mathrm{HCl}$ at $\mathrm{pH}$ 8.0, $1 \mathrm{mM}$ PMSF, 01.\% NP-40, $5 \mathrm{mM} \beta$-mercaptoethanol, 10\% glycerol), followed by a third purification step again using antiM2 agarose resin to capture the hSNM1A-Flag protein. The purification and basic characterization of recombinant hSNM1A (608-1040) will be described in detail elsewhere.

\section{Preparation of ICL-containing substrates}

The methodology used to prepare and purify DNA oligonucleotide duplexes containing a single site-directed ICL has recently been published in detail (Kiakos et al. 2010). See the Supplemental Material for further details.

\section{Nuclease assays}

ssDNA substrates were labeled at the $3^{\prime}$ end with $\left[{ }^{32} \mathrm{P}\right]-\alpha$-dATP (1 $\mu \mathrm{L} ; 0.37 \mathrm{MBq}$ ) and terminal deoxynucleotidyl transferase (20 U; Fermentas), and dsDNA substrates, after annealing where necessary, were labeled with $\left[{ }^{32} \mathrm{P}\right]-\alpha$-dATP and Klenow fragment lacking 3 '-exonuclease activity (5 U; New England Biolabs). To make singly nicked substrate, labeled DNA was incubated with Nt.CviPII (5 U; New England Biolabs). Exonuclease assays were carried out in $10-\mu \mathrm{L}$ reactions containing $20 \mathrm{mM}$ HEPES-KOH (pH 7.5), $50 \mathrm{mM} \mathrm{KCl}, 0.5 \mathrm{mM}$ DTT, $10 \mathrm{mM} \mathrm{MgCl}_{2}, 0.05 \%$ Triton-X, $0.1 \mathrm{mg} / \mathrm{mL}$ BSA, $5 \%$ glycerol, and the indicated amount of enzyme. The reactions were started by addition of radiolabeled substrate $(100 \mathrm{nM})$ and incubated for $30 \mathrm{~min}$ at $37^{\circ} \mathrm{C}$, followed by addition of $2 \mu \mathrm{L}$ of stop mixture $195 \%$ formamide, $10 \mathrm{mM}$ EDTA, $0.25 \%$ xylene cyanol, $0.25 \%$ bromophenol blue), heating at $95^{\circ} \mathrm{C}$ for $3 \mathrm{~min}$ to break down the crosslink, and placing on ice. The samples were analyzed on denaturing $20 \%$ polyacrylamide gels $(0.75 \mathrm{~mm})$ containing $0.5 \times$ TBE buffer and $7 \mathrm{M}$ urea. Gels were run at $275 \mathrm{~V}$ for $3 \mathrm{~h}$, dried, and exposed to a Kodak PhosphorImager screen and scanned using a Typhoon 9400 instrument (GE).

\section{Purification of XPF-ERCC1 and assay conditions}

This was performed as previously described (Enzlin and Scharer 2002). For XPF incision assays, $0.2 \mu \mathrm{g}$ of XPF-ERCC1 was incubated with substrate in $25 \mathrm{mM}$ HEPES-KOH (pH 8), $40 \mathrm{mM} \mathrm{KCl}$, $0.5 \mathrm{mM} \beta$-mercaptoethanol, $2 \mathrm{mM} \mathrm{MgCl}_{2}, 0.1 \mathrm{mg} / \mathrm{mL} \mathrm{BSA}$, and $10 \%$ glycerol for the indicated time period. Where hSNM1A was subsequently added, the reactions were carried out in $20 \mu \mathrm{L}$ of reaction buffer, as for the exonuclease reactions, containing 0.001 $\mu \mathrm{g}$ of $\Delta \mathrm{N}$-hSNM1A (30 min), followed by addition of $4 \mu \mathrm{L}$ of stop mixture. The samples were analyzed on denaturing $12 \%$ polyacrylamide gels $(0.75 \mathrm{~mm})$ containing $0.5 \times$ TBE buffer and $7 \mathrm{M}$ urea. Gels were run at $275 \mathrm{~V}$ for $1.5 \mathrm{~h}$, dried, and exposed to a medical X-ray film (Fuji).

\section{Post-labeling assays}

Substrate (100 nM) was mixed with reaction buffer, as for the $5^{\prime}$ exonuclease assay, in a final volume of $50 \mu \mathrm{L}$, and the reaction was initiated with addition of BSA or full-length hSNM1A WT or D736A $(0.05 \mu \mathrm{g})$. Reactions were allowed to proceed for $1 \mathrm{~h}$, after which $10 \mu \mathrm{L}$ of $5 \times$ WBB $(50 \mathrm{mM}$ Tris- $\mathrm{HCl}$ at $\mathrm{pH} 7.7,5 \mathrm{mM}$ EDTA, $5 \mathrm{M} \mathrm{NaCl}$ ) was added to the reaction, which was then transferred to a tube containing $10 \mu \mathrm{L}(50 \mu \mathrm{g})$ of washed (with $1 \times$ WBB) streptavidin M-280 beads (Invitrogen), allowing binding to proceed for $30 \mathrm{~min}$ at $37^{\circ} \mathrm{C}$. The unbound fraction was removed following sedimentation of beads in a magnetic rack. After washing (TE at $\mathrm{pH} 7.5,4^{\circ} \mathrm{C}$ ), water was added and the tubes were boiled for $3 \mathrm{~min}$ to break down the cross-link, and the resulting solution was collected after magnetic sedimentation of the beads as the bound fraction. Both unbound and bound fractions were labeled with $\left[{ }^{32} \mathrm{P}\right]-\gamma$-dATP $(1 \mu \mathrm{L} ; 0.37 \mathrm{Mbq})$ and T4 PNK (10 U; New England Biolabs) and analyzed by denaturing gel electrophoresis as described above.

\section{Acknowledgments}

We are very grateful to Ian Hickson, Leonard Wu, Val Macaulay, and Sovan Sarkar for helpful comments throughout this work and on the manuscript. We thank Lingzhi Gong and James McCullagh for acquiring mass spectrometry data. Spirogen Ltd. is gratefully acknowledged for supplying the drug SJG-136. Minoru Takata and Orlando Schärer kindly provided constructs of hSNM1A-EGFP and the purification of XPF-ERCC1, respectively. This work was supported by Cancer Research UK (grants C2259/A9994 to J.A.H., and CA9047/A10111 to P.M.). A.T.W. was supported by a New Zealand Top Achiever Doctoral Scholarship.

\section{References}

Ahkter S, Richie CT, Zhang N, Behringer RR, Zhu C, Legerski RJ. 2005. Snm1-deficient mice exhibit accelerated tumorigenesis and susceptibility to infection. Mol Cell Biol 25: 10071-10078.

Akkari YM, Bateman RL, Reifsteck CA, Olson SB, Grompe M. 2000. DNA replication is required To elicit cellular responses to psoralen-induced DNA interstrand cross-links. Mol Cell Biol 20: 8283-8289.

Andersson BS, Sadeghi T, Siciliano MJ, Legerski R, Murray D. 1996. Nucleotide excision repair genes as determinants of cellular sensitivity to cyclophosphamide analogs. Cancer Chemother Pharmacol 38: 406-416.

Aravind L, Walker DR, Koonin EV. 1999. Conserved domains in DNA repair proteins and evolution of repair systems. Nucleic Acids Res 27: 1223-1242.

Bae JB, Mukhopadhyay SS, Liu L, Zhang N, Tan J, Akhter S, Liu X, Shen X, Li L, Legerski RJ. 2008. Snm1B/Apollo mediates replication fork collapse and $S$ Phase checkpoint activation in response to DNA interstrand cross-links. Oncogene 27: 5045-5056.

Barber LJ, Ward TA, Hartley JA, McHugh PJ. 2005. DNA interstrand cross-link repair in the Saccharomyces cerevisiae cell cycle: overlapping roles for PSO2 (SNM1) with MutS factors and EXO1 during S phase. Mol Cell Biol 25: 2297-2309.

Ben-Yehoyada M, Wang LC, Kozekov ID, Rizzo CJ, Gottesman ME, Gautier J. 2009. Checkpoint signaling from a single DNA interstrand crosslink. Mol Cell 35: 704-715.

Berardini M, Foster PL, Loechler EL. 1999. DNA polymerase II (polB) is involved in a new DNA repair pathway for DNA interstrand cross-links in Escherichia coli. I Bacteriol 181: $2878-2882$. 
Bhagwat N, Olsen AL, Wang AT, Hanada K, Stuckert P, Kanaar R, D'Andrea A, Niedernhofer LJ, McHugh PJ. 2009. XPFERCC1 participates in the Fanconi anemia pathway of crosslink repair. Mol Cell Biol 29: 6427-6437.

Callebaut I, Moshous D, Mornon JP, de Villartay JP. 2002. Metallo- $\beta$-lactamase fold within nucleic acids processing enzymes: the $\beta$-CASP family. Nucleic Acids Res 30: 35923601.

Cattell E, Sengerova B, McHugh PJ. 2010. The SNM1/Pso2 family of ICL repair nucleases: from yeast to man. Environ Mol Mutagen 51: 635-645.

Chan KL, Palmai-Pallag T, Ying S, Hickson ID. 2009. Replication stress induces sister-chromatid bridging at fragile site loci in mitosis. Nat Cell Biol 11: 753-760.

Cole RS, Sinden RR. 1975. Repair of cross-linked DNA in Escherichia coli. Basic Life Sci 5B: 487-495.

Crossan GP, van der Weyden L, Rosado IV, Langevin F, Gaillard $\mathrm{PH}$, McIntyre RE, Gallagher F, Kettunen MI, Lewis DY, Brindle K, et al. 2011. Disruption of mouse Slx4, a regulator of structure-specific nucleases, phenocopies Fanconi anemia. Nat Genet 43: 147-152.

Damia G, Imperatori L, Stefanini M, D’Incalci M. 1996. Sensitivity of $\mathrm{CHO}$ mutant cell lines with specific defects in nucleotide excision repair to different anti-cancer agents. Int I Cancer 66: 779-783.

Demuth I, Digweed M, Concannon P. 2004. Human SNM1B is required for normal cellular response to both DNA interstrand crosslink-inducing agents and ionizing radiation. Oncogene 23: 8611-8618.

De Silva IU, McHugh PJ, Clingen PH, Hartley JA. 2000. Defining the roles of nucleotide excision repair and recombination in the repair of DNA interstrand cross-links in mammalian cells. Mol Cell Biol 20: 7980-7990.

Dronkert ML, Kanaar R. 2001. Repair of DNA interstrand crosslinks. Mutat Res 486: 217-247.

Dronkert ML, de Wit J, Boeve M, Vasconcelos ML, van Steeg H, Tan TL, Hoeijmakers JH, Kanaar R. 2000. Disruption of mouse SNM1 causes increased sensitivity to the DNA interstrand cross-linking agent mitomycin C. Mol Cell Biol 20: 4553-4561.

Enzlin JH, Scharer OD. 2002. The active site of the DNA repair endonuclease XPF-ERCC1 forms a highly conserved nuclease motif. EMBO I 21: 2045-2053.

Fekairi S, Scaglione S, Chahwan C, Taylor ER, Tissier A, Coulon S, Dong MQ, Ruse C, Yates JR 3rd, Russell P, et al. 2009. Human SLX4 is a Holliday junction resolvase subunit that binds multiple DNA repair/recombination endonucleases. Cell 138: 78-89.

Fisher LA, Bessho M, Bessho T. 2008. Processing of a psoralen DNA interstrand cross-link by XPF-ERCC1 complex in vitro. I Biol Chem 283: 1275-1281.

Gregson SJ, Howard PW, Hartley JA, Brooks NA, Adams LJ, Jenkins TC, Kelland LR, Thurston DE. 2001. Design, synthesis, and evaluation of a novel pyrrolobenzodiazepine DNA-interactive agent with highly efficient cross-linking ability and potent cytotoxicity. J Med Chem 44: 737-748.

Gu J, Li S, Zhang X, Wang LC, Niewolik D, Schwarz K, Legerski RJ, Zandi E, Lieber MR. 2010. DNA-PKcs regulates a singlestranded DNA endonuclease activity of Artemis. DNA Repair (Amst) 9: 429-437.

Hanada K, Budzowska M, Modesti M, Maas A, Wyman C, Essers J, Kanaar R. 2006. The structure-specific endonuclease Mus81Emel promotes conversion of interstrand DNA crosslinks into double-strands breaks. EMBO J 25: 4921-4932.

Hazrati A, Ramis-Castelltort M, Sarkar S, Barber LJ, Schofield CJ, Hartley JA, McHugh PJ. 2008. Human SNM1A suppresses the
DNA repair defects of yeast pso2 mutants. DNA Repair (Amst) 7: 230-238.

Hejna J, Philip S, Ott J, Faulkner C, Moses R. 2007. The hSNM1 protein is a DNA 5'-exonuclease. Nucleic Acids Res 35: 61156123.

Hemphill AW, Bruun D, Thrun L, Akkari Y, Torimaru Y, Hejna K, Jakobs PM, Hejna J, Jones S, Olson SB, et al. 2008. Mammalian SNM1 is required for genome stability. Mol Genet Metab 94: 38-45.

Henriques JA, Moustacchi E. 1981. Interactions between mutations for sensitivity to psoralen photoaddition (pso) and to radiation (rad) in Saccharomyces cerevisiae. I Bacteriol 148: 248-256.

Hoy CA, Thompson LH, Mooney CL, Salazar EP. 1985. Defective DNA cross-link removal in Chinese hamster cell mutants hypersensitive to bifunctional alkylating agents. Cancer Res 45: $1737-1743$.

Ishiai M, Kimura M, Namikoshi K, Yamazoe M, Yamamoto K, Arakawa H, Agematsu K, Matsushita N, Takeda S, Buerstedde JM, et al. 2004. DNA cross-link repair protein SNM1A interacts with PIAS1 in nuclear focus formation. Mol Cell Biol 24: 10733-10741.

Jachymczyk WJ, von Borstel RC, Mowat MR, Hastings PJ. 1981. Repair of interstrand cross-links in DNA of Saccharomyces cerevisiae requires two systems for DNA repair: the RAD3 system and the RAD51 system. Mol Gen Genet 182: 196-205.

Kiakos K, Hartley JM, Hartley JA. 2010. Measurement of DNA interstrand crosslinking in naked DNA using gel-based methods. Methods Mol Biol. 613: 283-302.

Kim Y, Lach FP, Desetty R, Hanenberg H, Auerbach AD, Smogorzewska A. 2011. Mutations of the SLX4 gene in Fanconi anemia. Nat Genet 43: 142-146.

Kuraoka I, Kobertz WR, Ariza RR, Biggerstaff M, Essigmann JM, Wood RD. 2000. Repair of an interstrand DNA cross-link initiated by ERCC1-XPF repair/recombination nuclease. J Biol Chem 275: 26632-26636.

Li X, Moses RE. 2003. The $\beta$-lactamase motif in Snm 1 is required for repair of DNA double-strand breaks caused by interstrand crosslinks in S. cerevisiae. DNA Repair (Amst) 2: 121-129.

Li X, Hejna J, Moses RE. 2005. The yeast Snm1 protein is a DNA 5'-exonuclease. DNA Repair (Amst) 4: 163-170.

Ma Y, Pannicke U, Schwarz K, Lieber MR. 2002. Hairpin opening and overhang processing by an Artemis/DNA-dependent protein kinase complex in nonhomologous end joining and V(D)J recombination. Cell 108: 781-794.

Magana-Schwencke N, Henriques JA, Chanet R, Moustacchi E. 1982. The fate of 8-methoxypsoralen photoinduced crosslinks in nuclear and mitochondrial yeast DNA: comparison of wildtype and repair-deficient strains. Proc Natl Acad Sci 79: 17221726.

Meniel V, Magana-Schwencke N, Averbeck D. 1995. Preferential repair in Saccharomyces cerevisiae rad mutants after induction of interstrand cross-links by 8 -methoxypsoralen plus UVA. Mutagenesis 10: 543-548.

Miller RD, Prakash L, Prakash S. 1982. Genetic control of excision of Saccharomyces cerevisiae interstrand DNA cross-links induced by psoralen plus near-UV light. Mol Cell Biol 2: 939-948.

Minko IG, Harbut MB, Kozekov ID, Kozekova A, Jakobs PM, Olson SB, Moses RE, Harris TM, Rizzo CJ, Lloyd RS. 2008. Role for DNA polymerase $\kappa$ in the processing of N2-N2guanine interstrand cross-links. J Biol Chem 283: 17075-17082.

Mu D, Bessho T, Nechev LV, Chen DJ, Harris TM, Hearst JE, Sancar A. 2000. DNA interstrand cross-links induce futile repair synthesis in mammalian cell extracts. Mol Cell Biol 20: $2446-2454$ 
Muniandy PA, Thapa D, Thazhathveetil AK, Liu ST, Seidman MM. 2009. Repair of laser-localized DNA interstrand cross-links in G1 phase mammalian cells. J Biol Chem 284: 27908-27917.

Nakanishi K, Cavallo F, Perrouault L, Giovannangeli C, Moynahan ME, Barchi M, Brunet E, Jasin M. 2011. Homology-directed Fanconi anemia pathway cross-link repair is dependent on DNA replication. Nat Struct Mol Biol 18: 500-503.

Niedernhofer LJ, Odijk H, Budzowska M, van Drunen E, Maas A, Theil AF, de Wit J, Jaspers NG, Beverloo HB, Hoeijmakers JH, et al. 2004. The structure-specific endonuclease Ercc1-Xpf is required to resolve DNA interstrand cross-link-induced double-strand breaks. Mol Cell Biol 24: 5776-5787.

Noll DM, Mason TM, Miller PS. 2006. Formation and repair of interstrand cross-links in DNA. Chem Rev 106: 277-301.

Norman D, Live D, Sastry M, Lipman R, Hingerty BE, Tomasz M, Broyde S, Patel DJ. 1990. NMR and computational characterization of mitomycin cross-linked to adjacent deoxyguanosines in the minor groove of the d(T-A-C-G-T-A).d(T-A-C-G-T-A) duplex. Biochemistry 29: 2861-2875.

Rahman KM, Thompson AS, James CH, Narayanaswamy M, Thurston DE. 2009. The pyrrolobenzodiazepine dimer SJG136 forms sequence-dependent intrastrand DNA cross-links and monoalkylated adducts in addition to interstrand crosslinks. I Am Chem Soc 131: 13756-13766.

Raschle M, Knipscheer P, Enoiu M, Angelov T, Sun J, Griffith JD, Ellenberger TE, Scharer OD, Walter JC. 2008. Mechanism of replication-coupled DNA interstrand crosslink repair. Cell 134: 969-980.

Sarkar S, Davies AA, Ulrich HD, McHugh PJ. 2006. DNA interstrand crosslink repair during G1 involves nucleotide excision repair and DNA polymerase zeta. EMBO J 25: 1285-1294.

Shen X, Do H, Li Y, Chung WH, Tomasz M, de Winter JP, Xia B, Elledge SJ, Wang W, Li L. 2009. Recruitment of fanconi anemia and breast cancer proteins to DNA damage sites is differentially governed by replication. Mol Cell 35: 716-723.

Siede W, Brendel M. 1982. Interactions between genes controlling sensitvity to radiation (RAD) and to alkylation by nitrogen mustard (SNM1) in yeast. Curr Genet 5: 33-38.

Sladek FM, Munn MM, Rupp WD, Howard-Flanders P. 1989. In vitro repair of psoralen-DNA cross-links by RecA, UvrABC, and the 5'-exonuclease of DNA polymerase I. I Biol Chem 264: 6755-6765.

Smeaton MB, Hlavin EM, McGregor Mason T, Noronha AM, Wilds CJ, Miller PS. 2008. Distortion-dependent unhooking of interstrand cross-links in mammalian cell extracts. Biochemistry 47: 9920-9930.

Stoepker C, Hain K, Schuster B, Hilhorst-Hofstee Y, Rooimans MA, Steltenpool J, Oostra AB, Eirich K, Korthof ET, Nieuwint AW, et al. 2011. SLX4, a coordinator of structure-specific endonucleases, is mutated in a new Fanconi anemia subtype. Nat Genet 43: 138-141.

Svendsen JM, Smogorzewska A, Sowa ME, O'Connell BC, Gygi SP, Elledge SJ, Harper JW. 2009. Mammalian BTBD12/SLX4 assembles a Holliday junction resolvase and is required for DNA repair. Cell 138: 63-77.

Van Houten B, Gamper H, Holbrook SR, Hearst JE, Sancar A. 1986. Action mechanism of $\mathrm{ABC}$ excision nuclease on a DNA substrate containing a psoralen crosslink at a defined position. Proc Natl Acad Sci 83: 8077-8081.

Wilborn F, Brendel M. 1989. Formation and stability of interstrand cross-links induced by cis- and trans-diamminedichloroplatinum (II) in the DNA of Saccharomyces cerevisiae strains differing in repair capacity. Curr Genet 16: 331-338.

Yang K, Moldovan GL, D'Andrea AD. 2010. RAD18-dependent recruitment of SNM1A to DNA repair complexes by a ubiquitin-binding zinc finger. J Biol Chem 285: 19085-19091. 


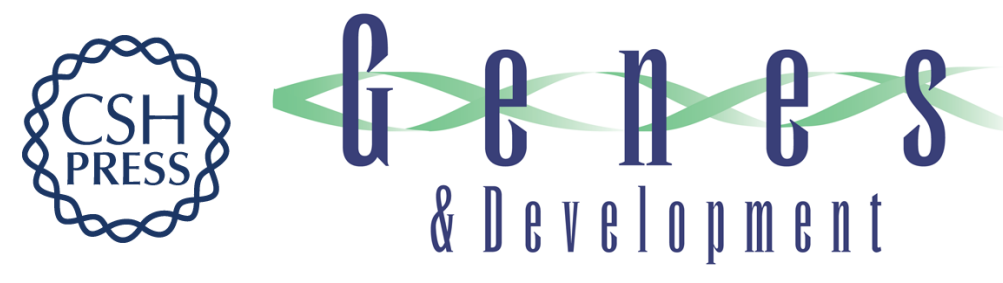

\section{Human SNM1A and XPF-ERCC1 collaborate to initiate DNA interstrand cross-link repair}

Anderson T. Wang, Blanka Sengerová, Emma Cattell, et al.

Genes Dev. 2011, 25:

Access the most recent version at doi:10.1101/gad.15699211

Supplemental http://genesdev.cshlp.org/content/suppl/2011/09/07/25.17.1859.DC1
Material

References This article cites 60 articles, 22 of which can be accessed free at:

http://genesdev.cshlp.org/content/25/17/1859.full.html\#ref-list-1

License

Email Alerting Receive free email alerts when new articles cite this article - sign up in the box at the top

Service right corner of the article or click here.

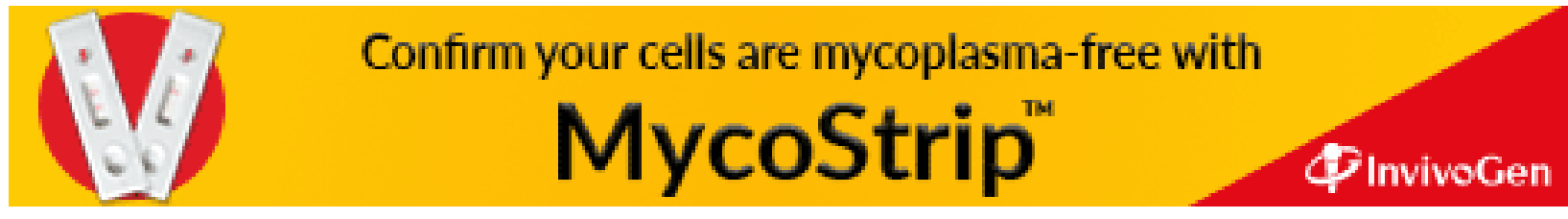

